\title{
Educação para os dissidentes. Há alternativas?
}

\author{
Cláudia Valéria Fonseca da Costa Santamarina ${ }^{1}$
}

\section{Resumo}

Este artigo reflete sobre a inépcia do sistema de ensino em responder a demanda por novas práticas pedagógicas e revisão de conteúdos curriculares. Como um mecanismo que reforça a ideia de fracasso dos diferentes e despolitiza a inadaptabilidade dos excluídos à colonialidade do saber, desconsidera sistematicamente os motivos da evasão escolar ressaltados pelos que estão fora da escola e pelos debates acadêmicos, revelando- se estratégica, tal como uma arquitetura de reprodução de poder neoliberal, que impede que novas práticas pedagógicas viabilizem uma produção de conhecimento, não para o outro - mercado, mas para si e em favor da autonomia e cidadania. Palavras-chave: Educação para Minorias; Pedagogia Eurocentrada, Racismo Institucional; Racismo Epistêmico; Inépcia Estratégica.

\section{Education for dissidents. Are there alternatives?}

\section{Abstract}

This article reflects on the ineptitude of the education system in responding to the demand for new pedagogical practices and review of curricular contents. As a mechanism that reinforces the idea of failure of the different and depoliticizes the inadaptability of the excluded to the coloniality of knowledge, systematically disregards the reasons for school dropout highlighted by those who are out of school and academic debates, revealing itself as strategic architecture of reproduction of neoliberal power, which prevents new pedagogical practices from enabling a production of knowledge, not for the other - market, but for oneself and in favor of autonomy and citizenship. Keywords: Education for Minorities; Eurocentred Pedagogy; Institutional Racism; Epistemic Racism; Strategic Ineptitude.

\section{Introdução}

Um mundo de dissidentes circula periférico e inacessível pelas bordas da educação no Brasil. Doze milhões de analfabetos no Brasil, mais que a população inteira de Portugal. Cerca de vinte e cinco milhões de pessoas entre quatorze e vinte e nove anos fora da escola - oito vezes a população do Uruguai. Os níveis mais baixos de educação têm cor: Não branca. Segundo a Pesquisa Nacional por Amostra de Domicílios Contínua, 10,6 \% de jovens pretos ou pardos com 18 anos ou mais ainda não sabem ler ou escrever contra $4,4 \%$ dos brancos. $22,2 \%$ dos brancos tem nível superior e apenas $8,8 \%$ da população preta ou parda consegue se graduar. Sobre os não-brancos ciganos ou indígenas nada se sabe oficialmente. Não há recorte étnico nos censos.

\footnotetext{
${ }^{1}$ Universidade Federal do Rio de Janeiro, Rio de Janeiro, claufcost@gmail.com.
} 
Há mais de 896 mil indígenas, distribuídos em 305 etnias (IBGE, 2017). Não há dados sobre o número de ciganos e nem em quantas etnias estão distribuídos. Sabe-se que entre os ciganos no Brasil estão os Calon, Rom e Sinti e que a escolaridade é baixa. No entanto, nenhuma das recomendações do I Encontro Nacional dos Povos Ciganos, promovido pelo Governo Federal em 2013, tiveram encaminhamento. A saber: instruir um mecanismo de identificação da população cigana nas escolas; elaborar e implementar programas e ações de alfabetização das populações ciganas; programas de alfabetização no Ensino de Jovens e Adultos para Povos Ciganos; política de combate ao preconceito e valorização dos Povos Ciganos nas escolas; inclusão de conteúdo sobre os Povos Ciganos em livros didáticos e no calendário escolar; formação para professores com participação de lideranças ciganas na elaboração e aplicação dos conteúdos; monitoramento da rede pública e privada de ensino quanto aos conteúdos sobre os Povos de Cultura Cigana nos materiais didáticos; intensificação das ações nos municípios e estados para efetiva aplicação da Resolução 03/2012 do CNE/CEB (BRASIL, 2013). Os recortes de análise tomam como base a autodeclaração de cor da pele o que torna os membros de diferentes etnias ciganas e indígenas absolutamente invisíveis em termos de iniquidades quanto ao acesso aos bens e serviços públicos, agrupados pelo censo como brancos, pardos, negros ou amarelos, indistintamente.

As análises disponíveis sobre o analfabetismo e a evasão escolar não aportam informações interseccionais que sobreponham categorias relacionadas à opressão, dominação ou discriminação, como raça/etnia, classe social e gênero.

Entretanto, ainda que não se possa avançar muito em análises sobre a escolarização de não brancos por meio dos dados oficiais, sabe-se que entre os 24,8 milhões de jovens entre 14 e 29 anos de idade que não frequentavam a escola em 2016, 24,1\% dos homens e 14 , $1 \%$ das mulheres disseram que não tinham interesse no ensino formal; $50,5 \%$ dos homens e $30,5 \%$ das mulheres disseram que não frequentavam porque estavam trabalhando, procurando trabalho ou conseguiram um trabalho que iria começar em breve; e 0,8\% dos homens e $26,1 \%$ das mulheres justificaram sua ausência da escola por ter que cuidar dos afazeres domésticos ou de criança, adolescente, idosos ou pessoa com necessidades especiais (IBGE, 2017).

O que fazer com esse saber?

O que fazer com o não reconhecimento de milhões de indivíduos sobre o valor da educação, nem sobre a lei que conclama ao ensino fundamental obrigatório ou sequer sobre a assertiva de que 
o estudo profissionalizante seria pivô do desenvolvimento? O que fazer com os adolescentes que tão logo chegam a alguma condição de autonomia desistem do estado de estudantes? O que fazer com a difícil tarefa de ensinar o que não lhes causa sentido? O que fazer com a necessidade que as crianças e adolescentes mais vulneráveis tem de trabalhar, ganhar dinheiro para contribuir na sua própria sobrevivência e da família? O que fazer com as diferenças culturais que aportam outros valores e demandas sociais aos seus entes não alinhados ao mercado capitalista?

\section{A inépcia estratégica do sistema educativo}

Santos (2010) propôs, como metáfora, que o mundo foi dividido por uma linha invisível que separou os países autonomeados desenvolvidos do Norte imperial, colonial e neocolonial dos países subdesenvolvidos do Sul colonizado, silenciado e oprimido. Esta divisão evidenciaria as dominações econômicas, políticas e culturais, traduzidas tanto pela hierarquização dos saberes como pela negação da diversidade. Para o autor, populações do Sul não têm realidade ou, no máximo, suas realidades devem estar vinculadas aos interesses do Norte operacionalizados por meio da apropriação e da violência. O pensamento abissal, instituído pelo Norte e plasmado pelas colonizadas governanças do Sul, com sua capacidade de produzir e radicalizar distinções no campo do conhecimento entre o que é útil e inútil, verdadeiro e falso, real e imaginário (Santos, 2010), rechaça a massa de analfabetos e não escolarizados à condição de não-existência. Qual política pública de educação se ocupa de tratar da inacessibilidade a (e da) massa de fracassados escolares no (ao) sistema de ensino? Por que a meta de torná-los alfabetizados ou capacitados a algum tipo de profissão não considera nenhuma mudança pedagógica, metodológica ou de conteúdo?

A realidade insiste: mantê-los na escola é ainda mais difícil do que os atrair e, quando se trata de um país com a dimensão geográfica e características populacionais do Brasil, essa hierarquização do saber, que denega a necessidade de um fazer atento às diversidades e desigualdades, torna-se estopim de violências cotidianas que afetam toda a população.

A ciência moderna eurocentrada monopolizou os bancos escolares dos países ocidentais posicionando-se como absoluta em sua legitimidade e negando aos demais saberes as qualidades de críveis e válidos (LANDER, 2005; FOUCAULT, 2013). Crenças, opiniões, 
entendimentos intuitivos ou subjetivos, não figuram como elementos de uma epistemologia acerca de si mesmos - sujeitos - sobre o objeto escolarização. A irrelevância do ensino, destacada por 9 milhões de jovens entre 14 e 29 anos de idade, que estavam fora da escola em 2016, é desconsiderada como conhecimento válido e legítimo.

O que se ensina na escola contemporaneamente é irrelevante dizem nove milhões de jovens e seu dizer permanece ignorado e subsumido ao conjunto de narrativas sobre os intratáveis, ineducáveis, insuficientes, ineptos, fracassados. A percepção da falta de sentido entre os conteúdos que lhes são apresentados e o que a necessidade de sobreviver reclama, não se reverte em inovações pedagógicas.

O governo insiste nos parâmetros pedagógicos tradicionais (BRASIL, 1997). Produtores de conteúdo repetem modelos restritivos. Educadores transferem o cabedal aos aprendizes. E os críticos apontam relações entre a baixa escolaridade e o desemprego ou a violência. Com todo o debate acadêmico e dos movimentos sociais contra o racismo e sobre o Eurocentrismo, o que ainda se lê em um livro didático contemporâneo de História para o 5o ensino fundamental, por exemplo, logo na primeira unidade dedicada à Independência do Brasil, é a descrição da chegada da família real ao Rio de Janeiro: “Em 1808 chegaram ao Brasil a rainha de Portugal, dona Maria, seu filho, o príncipe dom João, toda a Família Real e também a corte portuguesa. Você sabe por que isso ocorreu? Para entender, vamos ver o que acontecia na Europa nessa época" (FURNARI; LUNGOV, 2014, p.11).

Ver o que acontecia na Europa continua sendo primordial. A relevância permanece colonial. Não há a menor alusão a quem vivia aqui, como vivia, que efeitos a chegada da família colonizadora teve para os habitantes não-europeus e suas consequências que desenham as sociedades atuais. Negros são citados de forma acessória, indígenas secundarizados e ciganos banidos de Portugal para o Brasil ainda no final dos anos 1500 - sequer são mencionados. O foco principal da narrativa é o desenvolvimento que a chegada da corte portuguesa trouxe para o Brasil. Como apêndice à ode aos portugueses, as autoras sinalizam rapidamente que

A independência não alterou, porém, a principal característica da sociedade brasileira: a escravidão. Assim, para a maioria da população, que era formada por africanos escravizados, indígenas e trabalhadores livres e pobres, o 7 de setembro não trouxe grandes mudanças (FURNARI; LUNGOV, 2014, p.19). 
A violência da política escravagista não é definida ou tratada em nenhuma linha dos capítulos que tratam da Independência do Brasil, voltadas para estudantes na faixa etária de 10 a 11 anos, tal a naturalização da escravidão. Tão pouco são reveladas as tensões, lutas, resistências aos processos políticos da época. Representação inequívoca de que os ancestrais das crianças negras, indígenas, ciganas ou pobres as quais se dirigem os textos, não existem, não são pontos de interesse para a história ou para o mundo civilizado. Somente sobre os ascendentes europeus dos brancos importa saber e decorar. Textos didáticos suprimem cenários de resistência e luta que tiveram à frente os não-brancos, mesmo indígenas ou os ainda escravizados, inspirados na política liberal-francesa, lutando pelo fim do colonialismo e da escravidão. A abordagem positivista da história, apoiada na invenção dos "fatos" verdadeiros e inquestionáveis desconecta o passado do presente, limpa o que não pode ser dito e despreza o próprio processo de construção do discurso, que só apresenta as fontes que corroboram a manutenção do estado de poder, separando as narrativas ensináveis da vida dos ensinados (TROUILLOT, 2015; PEREIRA; ARAÚJO, 2017).

Nada sobre a sociedade estruturada sob o regime da escravidão. Nada sobre centenas de negros fugidos das fazendas da região que formavam quilombos nas matas da Serra da Carioca. Nada sobre o temor da população branca e proprietária em relação a presença de negros escravizados e homens livres pobres na cidade. A Conspiração dos Alfaiates ou Conjuração Baiana, em 1798, na Bahia, que precedeu, por exemplo, a chegada da família real e queria romper com os laços coloniais, assim como a Inconfidência Mineira, são totalmente invisibilizadas e desassociadas do processo de luta política que culminou na independência do Brasil. O enforcamento dos alfaiates João de Deus e Manuel Faustino dos Santos e dos soldados Lucas Dantas e Luiz Gonzaga, líderes da revolta, não compõem o contexto do grito do Ipiranga. E mesmo quando faz referência ao que estava acontecendo na Europa, passeia por uma disputa em tom quase amigável entre a França de Napoleão e a Inglaterra, sem mencionar os efeitos de libertação e luta por autonomia nas colônias desde a Revolução Francesa e a Declaração dos Direitos do Homem nas colônias não é nem de longe pincelado.

Nada sobre a insegurança social dos brancos do reino pela possibilidade do tal "haitianismo" - insurreição de negros escravizados ou mestiços - como eram chamados vários levantes inspirados na Revolução em Saint Domingue que, quatro anos antes da chegada da família 
real ao Brasil, em 1804, venceu a colonização francesa, eliminou a escravidão e levou o Haiti à independência, tornando-o a primeira república governada por pessoas de ascendência africana.

Nada sobre as petições por alforria que os negros faziam ao príncipe regente e que ameaçavam seus senhores e senhoras. Os negros escravizados, embora não tivessem muitos recursos políticos, conheciam os mecanismos e as relações de poder. "No Brasil da segunda metade do século XIX, eles identificaram rapidamente as brechas abertas pelo tímido liberalismo vigente e frequentemente levaram seus senhores aos tribunais em defesa de direitos garantidos em lei" (REIS, 1996, p.35).

Nada sobre a prática dos milicianos negros no Rio de Janeiro de usarem, em 1805, medalhões pendurados no pescoço com o rosto Jean-Jacques Dessalines, em reverência ao líder da proclamação da independência haitiana, e nem que, em 1814, na Bahia, os escravizados falassem abertamente nas ruas sobre os sucessos no Caribe (REIS, 1996).

Nada sobre a Revolução Pernambucana de 1817 mobilizada pela insatisfação com a estrutura política e privilégios da monarquia e que, inspirada no iluminismo francês, queria elaborar uma Constituição e implantar um regime republicano no Brasil (MOURÃO, 2009). Apagada da história a resistência, crianças e adolescentes não aprendem que o movimento social prendeu o governador, implantou um governo provisório, abaixou impostos e libertou presos políticos, sendo derrotado, segundo Mourão (2009), porque D. João investiu em forte repressão militar condenado os líderes à morte.

A Revolução de 1817, ao engajar a participação ativa, política, administrativa e militar de negros escravos e libertos e mulatos, indistintamente, ao lado dos brancos, ao proclamar alto e bom som que 'deseja uma emancipação, que não permita mais lavrar entre eles o cancro da escravidão' e que não pode 'acreditar que os homens por mais, ou menos tostados degenerassem do original tipo de igualdade', não poderia indicar, naquela época, aos que não lhe eram simpáticos, senão um caminho em direção ao haitianismo. Os partidários da Monarquia rapidamente compreenderam essa lição, e a república foi imediatamente associada àquela noção de barbárie igualitária. Deste modo, a revolta haitiana, filtrada pelos acontecimentos de 1817, interferiria profundamente na história do Brasil, contribuindo para o fortalecimento das hostes monarquistas e para a caracterização do espírito republicano como extremista e condutor à desestruturação social, política e econômica (MOURÃO, 2009, p.172). 
Crianças e adolescentes aprendem que Dom Pedro gostava muito do Brasil e que foi intimado a voltar para Portugal. Aclamado a ficar no Brasil, decidiu torná-lo independente, numa franca despolitização dos processos sociais da época, conforme trecho reproduzido abaixo:

Em Portugal, havia forte pressão dos portugueses para que dom Pedro também voltasse. A presença de um membro da Família Real no Rio de Janeiro dificultava os planos de fazer o Brasil voltar a ser colônia. Políticos brasileiros, percebendo as intenções dos portugueses, iniciaram campanhas para que o príncipe regente permanecesse no Brasil. [...] Depois que dom Pedro decidiu permanecer no Brasil, o movimento pela independência ganhou força (FURNARI; LUNGOV, 2014, p.30-31).

Inúmeras foram rebeliões promovidas por negros escravizados, a Revolta dos Malês entre elas, e que poderiam espelhar a vontade de liberdade dos ancestrais dos estudantes afrodescendentes, por exemplo. Mas, o que é tratado sobre o Período Regencial, entre a abdicação de D. Pedro I e o chamado "Golpe da Maioridade" de D. Pedro II, só faz referência às vitórias dos patriarcas brancos. O que poderia representar a reunião de cerca de 600 negros africanos escravizados de várias etnias, com o protagonismo de nagôs e com a participação de huassás? Que os africanos aqui escravizados tinham várias etnias e crenças? Representaria o reconhecimento da diversidade? Da força política de dissidentes? Registraria a oposição às práticas de escravidão e à intolerância religiosa herdadas do sistema colonial português, somente vencidas por força das armas e do enforcamento? (MOURÃO, 2009).

O silenciamento do passado para a construção da história permanece sustentando a divisão abissal entre o Norte e o Sul e os interesses exploratórios do mercado. A conexão da história com a realidade atual das crianças e jovens, também violenta e herdeira de um conjunto de ações governamentais passadas, submerge suplantada pela situação europeia de conquistas e as estratégias de Napoleão.

E se negros devem permanecer inexistentes no contexto de colonização e independência, indígenas e ciganos um tanto mais. Nada sobre a guerra aos Botocudos, por exemplo, que viviam como nômades ocupando extensas áreas da Mata Atlântica, fixados pelos brancos na imagem de cruéis, antropófagos e sanguinários. Nenhum livro didático reproduz a decisão política que o Príncipe Regente tornou pública em sua Carta Régia de 13 de maio de 1808: 
Sendo-me as graves queixas da Capitania de Minas Geraes têm subido á minha real presença, sobre as invasões que diariamente estão praticando os indios Botocudos, antropophagos, em diversas e muito distantes partes da mesma Capitania, particularmente sobre asmargens do Rio Doce e rios que no mesmo desaguam e onde não só devastam todas as fazendas sitas naquellas visinhanças e tem até forçado muitos proprietarios a abandonal-as com grave prejuizo seu e da minha Real Coroa (...) Que desde o momento, em que receberdes esta minha Carta Regia, deveis considerar como principiada contra estes Indios antropophagos uma guerra offensiva que continuareis sempre em todos os annos nas estações seccas e que não terá fim, senão quando tiverdes a felicidade de vos senhorear de suas habitações e de os capacitar da superioridade das minhas reaes armas de maneira tal que movidos do justo terror das mesmas, peçam a paz e sujeitando-se ao doce jugo das leis e promettendo viver em sociedade, possam vir a ser vassallos uteis, como ja o são as immensas variedades de Indios que nestes meus vastos Estados do Brazil se acham aldeados e gozam da felicidade que é consequencia necessaria do estado social (...) (BRASIL, 1808).

Como dizer que os botocudos resistiram como puderam à guerra e às armas reais dos brancos dispostos a conquistar e dominar suas terras e subjugar suasfamílias? Como mostrar aos estudantes que a família real e jesuítas orientaram a ocupação da bacia do rio Tibagi e a invasão dos campos do cacique Kaingang Inhoó, pelos grandes fazendeiros paranaenses na expansão de seus domínios? Registrar, como escreveu Mota (1997), que a guerra da conquista se estendeu pelo século XX, até 1996, sustentando o saque e invasão sistemática - com apoio institucional ou por ações isoladas de fazendeiros e agricultores da região - das terras da Reserva Indígena dos Kaingang em São Jerônimo da Serra? Como alertar para o fato de que ao eleger a miscigenação entre o branco, o negro e o índio como promotora do patriotismo e consolidação da nação, o Império omitiu a presença dos ciganos na composição da população e negando aos ciganos o direito a figurar na história? Como incorporar à história oficial disciplinar que, ao criar a Intendência Geral de Polícia da Corte e do Estado do Brasil, em 1808, o Príncipe Regente queria organizar uma polícia capaz de proteger a integridade da família real diante das ações de resistência, inspiradas nas ideias liberais francesas, que foram tratadas como subversivas? E deixar entrever que esta função de submeter o diferente às armas é o que ainda sustenta o imaginário policial repressor até os dias atuais?

Como trazer à luz o apoio dos higienistas para cooptar as famílias brancas de elite, letradas, que podiam educar os filhos e se aliarem ao Estado ao mesmo tempo em que campanhas de 
moralização e higiene eram destinadas aos não-brancos em ações policiais? Seria útil revelar, como nos disse Costa (1983), que as ações repressivas tinham o objetivo de manipular a solidariedade familiar contra seus membros insubordinados ou insatisfeitos, assim como visavam afastar dos centros urbanos as ameaças que negros, ciganos e indígenas poderiam oferecer às famílias brancos por seus hábitos categorizados como insalubres?

A política capitalista contemporânea, endossando a defesa de direitos humanos, tal como a primeira república de 1889 em relação aos ideais iluministas, ao apagar passados dissidentes estimula a falácia mercadológica de que o estudo garante o acesso à socialização, oportunidades de trabalho e melhor remuneração, inclusive para os pobres negros, ciganos ou indígenas. As narrativas destacadas pelo IBGE (2017) apontam que se a educação é encarnada consensualmente pelo discurso oficial como pilar fundamental para a construção de oportunidades e prosperidade da nação, o mesmo não pode ser dito em relação às oportunidades de prosperidade individual.

A Teoria do Capital Humano, ao reafirmar insistentemente e de modo acrítico que os investimentos em educação e saúde podem aprimorar as aptidões e habilidades dos indivíduos, tornando-os mais produtivos e influenciando positivamente nas taxas de crescimento dos países, afasta de qualquer possibilidade de incorporação de novas práticas, pois subtrai um elemento indispensável de análise de contexto: “[...] a raça converteu-se no primeiro critério fundamental para a distribuição da população mundial nos níveis, lugares e papéis na estrutura de poder da nova sociedade. Em outras palavras, no modo básico de classificação social universal da população mundial" (QUIJANO, 2005, p.230).

Assim como o ideal de aperfeiçoamento das aptidões ignoram que as distinções de gênero, que regem a divisão sexual do trabalho, foram baseadas na "[...] reformulação liberal das ciências da vida e das ciências sociais no desmentido do pós-guerra, feito pelas elites governamentais e profissionais do ocidente [...]" e não reflete que "[...] essas reformulações deixaram de interrogar a história sociopolítica de categorias binárias tais como natureza/cultura, e também sexo/gênero, no discurso colonialista ocidental" (HARAWAY, 2004, p.217). Ou seja: a educação para o mercado se sustenta na narrativa do capital humano que destina o trabalho bem remunerado a poucas e bem definidas gentes - sempre mais humanas, tal como insinua a dúvida tão reincidente nas guerras e nas políticas assimilacionistas sobre a humanidade e civilidade dos 
não brancos e dos não heterossexuais.

Quando as teorias econômicas abstraem realidades sociais e insistem na ficção mercadológica ao atribuírem, por exemplo, às causas do desemprego várias razões desconectadas dos efeitos da colonialidade, elas favorecem a inépcia estratégica do sistema de ensino que lava as mãos para os desadaptados. Zylberstejn e Neto (1999), que comungam desta retórica, sintetizam que as várias razões para alguém estar desempregado estão concentradas em causas objetivas como: i. A primeira entrada no mercado de trabalho; ii. Reentrantes que ficaram fora do mercado por algum tempo; iii. Pedido de demissão; iv. Demissão por falência da empresa; ou v. Demissão por extinção de vaga ou dispensa temporária "devido a uma redução sazonal no nível de atividade econômica" (ZYLBERSTEJN; NETO, 1999, p.132). Localizando a origem estrutural do desemprego - tomando como estrutural a ausência de um "matching" entre habilidades requeridas pelo mercado e oferecidas pelos indivíduos - reduzem às qualidades de friccional (tempo para acontecer o tal matching), sazonal (por conta das flutuações inerentes ao sistema econômico) ou de demanda (por redução do número de vagas) qualquer causa de desemprego, levando portanto a entender como natural a ausência dos dissidentes e expropriados da educação básica. Não há entre as teorias econômicas sobre a desemprego baseadas no capital humano - Job Search, Substituição Intertemporal do Ciclo Econômico Real, Teoria da Sinalização; Job Signalling Model, Teoria dos Deslocamentos Setoriais, Teoria da Histerese -, nenhuma menção a inexistência de vagas para todos, ao racismo institucional que orienta a seleção de empregados ou mesmo uma remota compreensão do trabalho como mecanismo que não seja dar suporte às empresas (FAGGIAN, 2014; DORNBUSH; FISHER; STARTZ, 2013; ZYLBERSTEJN; NETO, 1999; MA;WEISS, 1993; LILIEN, 1982). Nenhuma das recomendações dos economistas para o desenvolvimento associa o desemprego à principal promessa neoliberal não cumprida, a saber: o mercado dará resposta às demandas individuais e o próprio crescimento econômico gerará a multiplicação da oferta de empregos e aumento geral da riqueza.

Ao definir a educação formal e a qualificação como razão principal para o desemprego cristaliza a ideia de que é a incapacidade individual que não se adequa às ofertas pretensamente existentes no mercado, transformando o caminho de chegada à prosperidade numa miragem enganosa comparável ao pote de ouro no final do arco-íris. Em contraposição, a evidência sensível no cotidiano de que não há bons empregos e salários para todos, alimenta a prerrogativa 
não declarada de que

Em suma, a ênfase nas virtudes econômicas da educação não descarta o inevitável reconhecimento de que a democratização do acesso às instituições escolares e a multiplicação das oportunidades educativas, o que faz é ampliar as vantagens dos portadores de educação na disputa pelos poucos espaços de bem-estar e riqueza que o 'desenvolvimento' econômico oferece. 'Mais educação para todos' significa assim, mais educação para competir melhor pelos 'nichos (como conceito apropriado em sua densidade necrológica) que o mercado reserva aos eleitos' (GENTILI, 2007, p.22).

O ensino para o mercado é redundante e desqualifica sempre os não-homens brancos, não proprietários, sem poder político. Qual interesse, portanto, as conquistas assépticas dos europeus sobre os menos valorosos brasileiros podem ter para uma criança negra, indígena ou cigana? De que modo pode haver uma identificação com o lugar mercadológico que a política neoliberal Ihe reserva? A reprodução colonial instaura o não sentido, a ruptura entre o que é ensinado e a necessidade das famílias. A pedagogia aliena e reafirma, assim, a lógica da educação para o branco e da polícia para o dissidente pobre, mecanismo sintetizável nessa espécie de inépcia estratégica, que amalgama os discursos institucionais de forma que as práticas sociais permaneçam imutáveis e excludentes, reprodutoras de narrativas racistas, sexistas e classistas que seguem seu curso mutilador e alienante, perpetuando a pedagogia de dominação.

O perfil das vítimas fatais de violência ou expropriadas dos direitos básicos à educação, saúde, alimento e habitação, continua composto por pessoas não brancas e com baixa escolaridade, desde a colonização. Segundo o Atlas da Violência (IPEA, 2017), 65,3\% das mulheres assassinadas no Brasil no último ano eram negras, o que evidencia a combinação perversa entre desigualdade de gênero e racismo. Em 2018, o Atlas da Violência registra que "a taxa de homicídios é maior entre as mulheres negras $(5,3)$ que entre as não negras $(3,1)$ - a diferença é de $71 \%$. Em relação aos dez anos da série, a taxa de homicídios para cada 100 mil mulheres negras aumentou $15,4 \%$, enquanto entre as não negras houve queda de $8 \%$ " (IPEA, 2018, p.51). Não é possível saber a realidade de mulheres indígenas e ciganas em relação a violência, em termos quantitativos, mas este panorama indica o cenário de violência letal contra a mulher no país. Uma nota pública a ONU Mulheres destaca que

Num contexto de defesa de territórios e exclusões sociais, as mulheres 
indígenas têm sido alvo de violências perversas baseadas em gênero, a exemplo de feminicídios, exploração sexual, tráfico de pessoas e agressões de outras naturezas que se acentuam na medida em que elas afirmam o seu protagonismo político em defesa dos seus povos e seus direitos" (ONU MULHERES BRASIL, 2016).

A sabedoria popular dos quatorze anos - idade em que as distorções idade-série disparam, suspeita: o que é necessário pensar, reter do que a escola diz? A ordem, a submissão e a memorização da ordem e da submissão. Todo o mais pode ser esquecido? Sim e efetivamente o é.

Estudar para o quê? Em troca do quê? Para ficar igual aos outros? Para ser parte da transformação social almejada pelos defensores do "desenvolvimento"? A realidade que urge em fome, sede, sexo, prazer e sono é mais forte do que ser mais um, no "moinho de gastar gentes" (RIBEIRO, 1995).

Embora seja inevitável ao educador estar enovelado pela educação bancária, uma vez que contratado pelo sistema educacional afinado ao capitalismo/neoliberalismo, urge ir além de depositar, transferir, transmitir valores e conhecimentos. Fazer com que o estudante transite da posição de objeto de adaptação e ajustamento a uma realidade mercadológica para a de sujeitos produtores de conhecimento e de visão de mundo crítica e plural.

Nenhuma formação docente verdadeira pode fazer-se alheada, de um lado, do exercício da criticidade que implica a promoção da curiosidade ingênua à curiosidade epistemológica, e do outro, sem o reconhecimento do valor das emoções, da sensibilidade, da afetividade, da intuição ou adivinhação. (FREIRE, 1996, p.20)

O educador pode romper a relação vertical prevista entre ele e estudante e que estimula a ingenuidade e não a criticidade? Pode desnudar pluriversos, a diversidade de sentidos e utilidades que existem nas disciplinas que estão em seu poder apresentar? Pode facilitar a correlação dos conteúdos com as realidades vividas pelos que a elas estão sendo apresentados? Pode subverter a inépcia estratégica e transformar a massa a ser homogeneizada em sujeitos criativos, que projetam, que se transformam, que almejam um uso próprio e pessoal do conhecimento? Há exemplos que sim (FREIRE, 1996). Mas, antes é preciso deixar de professar. É preciso saber da função social do que se ensina e reaprender o sentido de ser educador como instrumento de mudança que prepara para a cidadania e, portanto, para o enfrentamento do 
racismo, do sexismo e do classismo em suas mais variadas e espúrias formas de humilhação.

É preciso praticar e estimular pensamentos críticos, rizomáticos, nômades, inventivos, que sirvam para o si mesmo em devir. Contornar o que paralisa e incita à repetição estéril. Abrir mão da declamação e da reprodução, em nome da transformação dos currículos em novos conteúdos úteis. Entender que fração imprópria, sistema digestório, perímetro, variações linguísticas são palavras desconexas da realidade e tentar alguma associação. Ou aprendê-las continuará sendo, para mais 37 milhões de pessoas, perda de tempo, e para as demais, não brancas, escolarizáveis, uma tentativa permanentemente frustrada de se encaixar e sobreviver no mundo mercado.

\section{Referências}

BRASIL. Carta Régia de 13 de maio de 1808. v. 1, p.37 (Coleção de leis do Império do Brasil 1808). Disponível em:

http://www2.camara.leg.br/legin/fed/carreg_sn/anterioresa1824/cartaregia-40169-13- maio1808-572129-publicacaooriginal-95256-pe.html. Acesso: 04 jun. 2018

BRASIL. Secretaria de Educação Fundamental. Parâmetros curriculares nacionais: introdução aos parâmetros curriculares nacionais. Brasília: MEC/SEF, 1997.

BRASIL. Relatório Executivo I Semana Nacional dos Povos Ciganos - 20 a 24 de maio de 2013. Brasília: Secretaria de Políticas de Promoção da Igualdade Racial da Presidência da República, 2013.

COSTA, J. F. Ordem médica e norma familiar. São Paulo: Graal, 1983.

DORNBUSH, R.; FISCHER, S.; STARTZ, R. Macroeconomia. 11. ed. Porto Alegre: McGraw-Hill Education, 2013.

FAGGIAN, A. Job Search Theory. In: FISCHER, M.; NIJKAMP, P.(Eds.). Handbook of regional science. Berlin: Springer, 2014.

FREIRE, P. Pedagogia da autonomia: saberes necessários à prática educativa. São Paulo: Paz e Terra, 1996.

FOUCAULT, M. A arqueologia do saber. Rio de Janeiro: Forense Universitária, 2013.

FURNARI, R.; LUNGOV, M. Aprender juntos - História: 5 ano. Rio de Janeiro: Editora SM, 2014. 
GENTILI, P. Educar contra la humillación. Docencia, n.36, p.18- 23, dez. 2008.

HARAWAY, D. "Gênero" para um dicionário marxista: a política sexual de uma palavra. Cadernos Pagu, n.22, p.201-246, 2004.

INSTITUTO BRASILEIRO DE GEOGRAFIA E ESTATÍ́STICA - IBGE. PNAD Contínua 2016: 51\% da população com 25 anos ou mais do Brasil possuíam apenas o ensino fundamental completo. 2017. Disponível em: https://agenciadenoticias.ibge.gov.br/agencia-noticias/2013-agencia-denoticias/releases/18992-pnad-continua-2016-51-da-populacao-com-25-anos-ou-mais-do-brasilpossuiam-apenas-o-ensino-fundamental-completo.html. Acesso em: 18/05/2018.

INSTITUTO DE PESQUISA ECONÔMICA APLICADA - IPEA. Atlas da violência. Brasília: Ipea, 2017. INSTITUTO DE PESQUISA ECONÔMICA APLICADA - IPEA. Atlas da violência. Brasília: Ipea, 2018. LANDER, E. A colonialidade do saber: eurocentrismo e ciências sociais: perspectivas latinoamericanas. Buenos Aires: CLACSO, 2005.

LILIEN, D. M. Sectorial shifts and cyclical unemployment. Journal of Political Economy, v.90, n.4, p.777-793, 1982.

MA, C.; WEISS, A. M. A signaling theory of unemployment. European Economic Review, n.37, p.135-157, 1993.

MOTA, L. T. A guerra de conquista nos territórios dos índios Kaingang do Tibagi. Revista de História Regional, n.2, p.187-207, 1997.

MOURÃO, G. B. C. M. A. Revolução de 1817 e a história do Brasil: um estudo de história diplomática. Brasília: Fundação Alexandre de Gusmão, 2009.

ONU MULHERES BRASIL. Nota pública: ONU Mulheres alerta para violência contra mulheres indígenas e conclama garantia de direitos. Disponível em:

http://www.onumulheres.org.br/noticias/nota-publica-onu-mulheres-alerta-para-violenciacontra-mulheres-indigenas-e-conclama-garantia-de-direitos/. Acesso: 24 jun. 2018

PEREIRA, A.; ARAÚJO, M. Race, history, and education in Brazil and in Portugal: challenges and perspectives. Educação \& Realidade, Porto Alegre, v.42, n.1, p.139- 160, 2017.

QUIJANO, A. Colonialidade do poder, eurocentrismo e América Latina. In: LANDER, E (Org.). A colonialidade do saber: eurocentrismo e ciências sociais: perspectivas latino-americanas. Buenos Aires: CLACSO, 2005, p.107-130.

REIS, J. J. Quilombos e revoltas escravas no Brasil. Revista USP. São Paulo: USP, n.28, p.14-39, 1996. 
RIBEIRO, D. O povo brasileiro: a formação e o sentido do Brasil. São Paulo: Companhia das Letras, 1995.

SANTOS, B. S. A gramática do tempo. São Paulo: Cortez, 2010.

SMITH, S. W. Labour economics. Routhledge, 1994.

TROUILLOT, M-R. Silencing the past: power and the production of history. Boston: Beacon Press, 2015.

ZYLBERSTEJN, H; NETO, G. B. As teorias de desemprego e as políticas públicas de emprego. Estudos Econômicos, São Paulo: USP, n.1, p. 129-149, 1999.

Recebido em outubro de 2018.

Aprovado em setembro de 2019. 